\title{
The Soil Heavy Metals Element Release and Migration Characteristics of Hengshihe River Both Sides for Guangdong Dabaoshan
}

\author{
Su Wen-ji ${ }^{1}$, Fu Shan-ming ${ }^{2}$ \\ ${ }^{1}$ Academy of Civil and Transportation, South China University of Technology, Guangdong, China \\ ${ }^{2}$ School of Environmental Science and Engineering, Guangzhou University, Guangdong, Guangzhou, China \\ Email address: \\ tbyswj@163.com (Su Wen-ji), fushanming@qq.com (Fu Shan-ming)
}

\section{To cite this article:}

Su Wen-ji, Fu Shan-ming. The Soil Heavy Metals Element Release and Migration Characteristics of Hengshihe River Both Sides for Guangdong Dabaoshan. International Journal of Environmental Protection and Policy. Vol. 4, No. 3, 2016, pp. 49-57.

doi: 10.11648/j.ijepp.20160403.12

Received: February 29, 2016; Accepted: May 12, 2016; Published: May 19, 2016

\begin{abstract}
This paper through soil environment investigation and sampling analysis of Hengshihe River both sides of Shao guan Dabaoshan mining, along the route of the acidic mining waste water flows, and selected 6 research division of the Liangqiao, Shui louxia, Tangxin, Yanghe-lianxin, Shangba and Xiaba village, to analyze the pollution source and discusses the pollution element migration patterns and characteristics of Dabaoshan mine. The results show that the Dabaoshan mine original high background values of heavy metals pollution and the secondary pollution caused by mining activities of superimposition and accumulation is the important source of pollution. The migration ability of heavy metal elements in soil is $\mathrm{Cd}>\mathrm{Cu}>\mathrm{Pb}>$ zinc. The Cd elements have to be considered as an optimization control of soil restoration governance elements in Dabaoshan pollution area.
\end{abstract}

Keywords: Soil, Pollution Source, Release, Migration, Background Value

\section{Introduction}

Soil is an important part of the ecological environment. This is a research focus in the soil ecological and environmental risk issue for soil heavy metal pollution caused by mining activities, and these have caused pollution is not ended with the production of enterprises and closed. So the work of restore soil management is a long way to go, the cumulative effect of soil heavy metals, especially the research for the soil heavy metals element release and migration characteristics is great significance.

Guangdong Dabaoshan mining of mineral resources leads to the deterioration of the environment and ecological imbalance in the region, cause potential harm to residents of health. Since the serious consequences of heavy metal pollution of Dabaoshan was reported many times by media, its soil environmental problems were paid close attention to the government and academia. The environmental pollution problems caused by Dabaoshan polymetallic mining in the past has not been attended because of mismanagement, local protection and people environmental protection consciousness, the low expenditure on environmental protection. In the late $1990 \mathrm{~s}$, people gradually realized that Dabaoshan mining can't post-natal environmental protection, environmental protection investment must synchronize with mining, ore dressing, in the aspect of soil environmental protection and pollution control has made positive progress, both in the scientific research, capital investment, management, supervision and technical support. They have made great achievements. Since the 1960 s, the soil environmental protection work on the study of Dabaoshan mining area is roughly experienced the following three stages (Figure 1). 


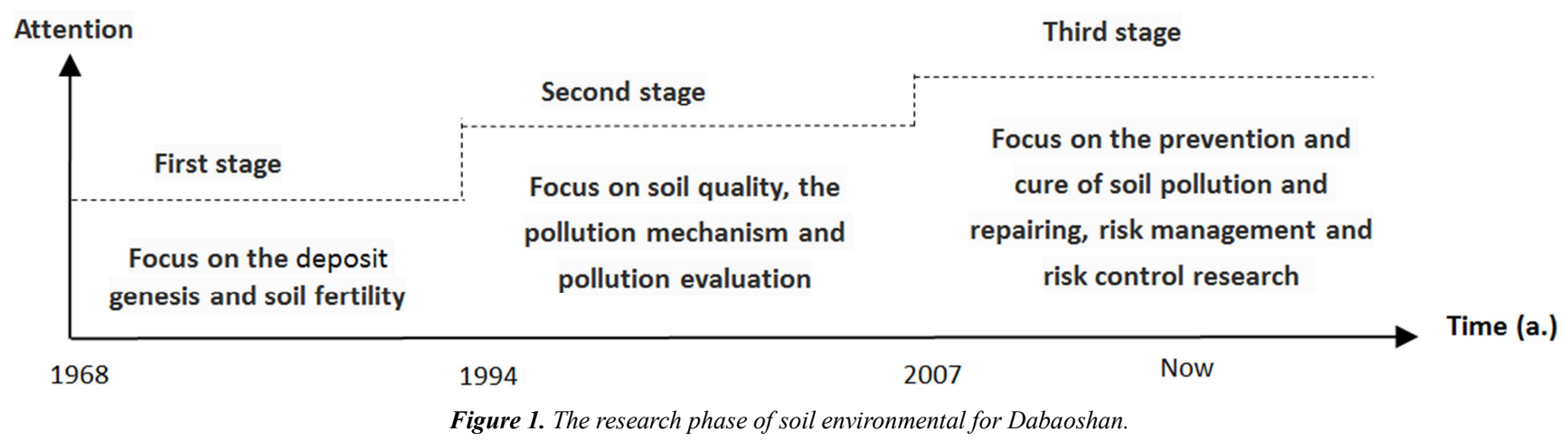

The predecessors' research work of Dabaoshan mining area, more focused on the deposit genesis [1-4], distribution characteristics and pollution evaluation [5-11], ecological risk and health risks evaluation [12-15], and so on. The researches show that soil heavy metal pollution elements of Dabaoshan mining area and the surrounding are mainly $\mathrm{Cd}, \mathrm{Pb}, \mathrm{Cu}$ and $\mathrm{Zn}$. At present, the focus in Shangba reclamation and control of heavy metal pollution of soil improvement and vegetation remnant [16-18], more based on the State Soil Environment Quality Standard (GB15618-1995) and the Guangdong Shao guan red soil background values studies [19-23]. But the evaluation parameters and index only used by Guangdong Shao guan red soil background values is inadequate because the Dabaoshan mining area of heavy metal element enrichment characteristics. Few studies of predecessors for Dabaoshan mining area about heavy metals element background values and man-made pollution law of superposition in the relationship among heavy metal distribution characteristics, accumulation, characteristics analysis and evaluation [24-28].

Therefore, this paper from the Dabaoshan mine area background values of heavy metals, not affected by the mining activity on the control of the value and with mining activities led to the superimposition and accumulation degree of correlation of pollution, comprehensive study within the scope of the mining area and the surrounding influence elements of main heavy metal pollution in soil $\mathrm{Cd}, \mathrm{Pb}, \mathrm{Cu}$ and zinc, its release and distribution regular pattern, which will provide a scientific basis for ecological risk assessment and early warning.

\section{The General Situation}

The scope of this study area is to east longitude $113^{\circ} 40^{\prime}$ $113^{\circ} 50^{\prime}$, north latitude $22^{\circ} 24^{\prime} \sim 24^{\circ} 35^{\prime}$. Geological environment impact area is about $65 \mathrm{~km}^{2}$. The overall terrain for lower from north to south, the north is an elevation of $800 \sim 1200$ m mountain; the south is low mountain hills and alluvial plains. The ore of Dabaoshan mining is mainly composed of chalcopyrite, galena, sphalerite, pyrite, molybdenite, black (white) tungsten, bismuthinite and pyrrhotite, etc. This is a super-large polymetallic opencast mine in Guangdong province [29-30].

The ecological environment of mining stope is destructed serious, the soil layer is shallow, strong acid, and water storage is very weak. So most of the rain and slope infiltration water directly erode the surface soil, slope, ore-bearing bed, and in the form of surface runoff flow down quickly. The wastewater acid is very high; contain $\mathrm{Cd}, \mathrm{Cu}, \mathrm{Pb}$, zinc and other heavy metals, and constantly moving from the mine to the downstream. At present, the mining waste discharge in two large tailing sand reservoirs of - Tie Long sediment tailing sand reservoir and FanDong (also known as CaoDuiken) tailings. Tie long tailing sand reservoir is located in the southwest of Dabaoshan mine, storage capacity is about 10 million $\mathrm{m}^{3}$. Sediment tailing sand reservoir is to prevent the soil with the flash floods mine inflow Hengshihe River from the top of the mountain water, but the tailing sand reservoir full of silt already, the acid water of tailing sand reservoir overflow dam crest flow downstream perennial, and gather in Hengshihe River. FanDong tailing sand reservoir is located in the northeast of the stope, and it was built in the 1970s, used to collect washing and recycling use the waste water of ores dressing. The original capacity is 1.05 million cubic, later heightening the dam and its capacity becomes 1.25 million cubic. By decades of use, the capacity is shrunk to 2 million cubic. Since 2007, 2 tailings were capacity enlarging reform, and building up a new wastewater processing factory and the corresponding wastewater pipeline, and the scale is $\mathrm{Q}=1.5 \times 10^{4} \mathrm{~m}^{3} / \mathrm{d}$.

The composition of soil parent materials in Dabaoshan mining area and the surrounding area has a great effect on soil chemical composition. The soil layer of the slope and Hengshi River upstream flood plain terrace at LiangQiao, Shui Louxia village is thinner. It is mainly comprised of coarse gravel soil, gravel and coarse sand. The soil layer of ShangBa and XiaBa village is thicker. It is an alluvial plain by Hengshi River downstream flow and Chen Gong river flows (not polluted by Dabaoshan mining) intersection formed with small particles to the clay and silt of river sediments deposited in there.

\section{Sample Collection and Analysis}

\subsection{Sample Collection}

To Dabaoshan mining as a starting point, along the both sides of Hengshi River, we collected the rock and soil samples at tailing sand reservoirs, Liang Qiao, Shui Louxia, Tang Xin, Yang He, Lian Xin, Shang $\mathrm{Ba}$ and Xia Ba village. (Figure 2) [32]. According to the actual level of soil profile, 
we collected topsoil, subsoil and weathered rocks for the residual soil, and ensure that the characteristics of the soil samples can represent each profile section; For both sides of alluvial soil and agricultural soil of Hengshi River, 104 surface soil samples (plough layer depth is $0-20 \mathrm{~cm}$ ) and 115 vertical section soil samples (sampling depth is $0-150 \mathrm{~cm}$ ) were collected by $200-400 \mathrm{~m}$ spacing for the parallel Hengshi River and $50-100 \mathrm{~m}$ spacing for the vertical rivers flow. At the same time, 9 soil samples as contrast values for evaluate the effect of the mining activity on heavy metal pollution and they were collected by Chen Gong River which almost not influenced by mining activities, the soil forming environment and the tillage methods are similar or identical to Hengshi River both sides. Drilling with Luoyang shovel, soil samples in the sample bags, serial number and record the sampling point coordinates at the same time.

\subsection{Sample Preparation}

The samples were spread into a thin layer on clean paper loosely and evenly, and placed indoor of cool and ventilated place dry naturally, rejects all impurities such as plant roots, porphyrization repeatedly. All the soil sampled were passed the sieve of diameter of $1 \mathrm{~mm}$, and then take some samples which are passed of $1 \mathrm{~mm}$ sieve, further grinding, the let them pass the sieve of 200 mesh, sieve samples mixed after all, grinding into the sealing bag sealed samples, label and record for heavy metal content analysis.

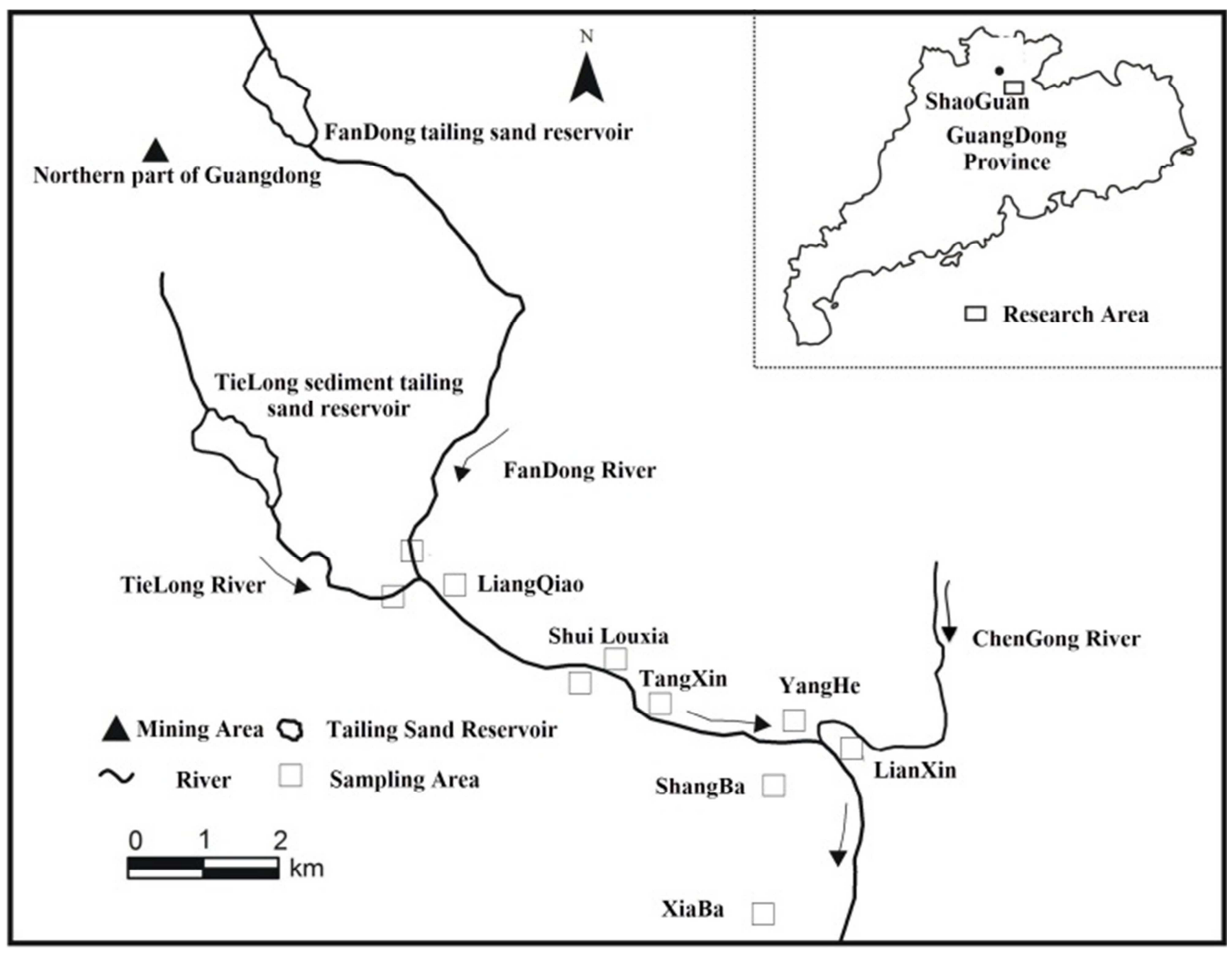

Figure 2. Research and sampling area.

\subsection{Sample Analysis Test}

The sample of $0.500 \mathrm{~g}$ is weighed and set in polytetrafluoroethylene crucible, wetted by high purity water, soaked with $10 \mathrm{~mL}$ aqua regia overnight, then heated steam to nearly dry at electric heating plate. Take off the electric heating plate for a moment then adding $5 \mathrm{~mL}$ flu hydric acid and continue to heat for drying. Take off the electric heating plate again for a moment then adding $5 \mathrm{~mL}$ perchlorate and continue to heat for drying. Removed, added $5 \%$ dilute nitric acid rinse crucible wall, dissolving in the salt at electric heating plate, remove and cooling it, and transfer the solution into $50 \mathrm{~mL}$ flask and prepared the test solution and shake well. In this experimental process, the parallel samples and standard samples, blank samples were joined, in order to ensure the accuracy of the data. All the content of heavy metal element of $\mathrm{Pb}, \mathrm{Cd}, \mathrm{Cu}$ and zinc for samples were determined with heavy metal concentration determination instrument ICP - MAS [33]. 


\section{Analysis and Discussion}

\subsection{Analyze the Heavy Metal Release Source on Both Sides of Hengshi River}

Soil parent material and material composition for soil chemical composition of parent rock is very obvious. Most mineral compositions of soil materials come from the primary mineral particles and all kinds of secondary minerals inherited of Pedogenic parent material. Therefore, the content of heavy metal elements in soil and its distribution characteristics not only depends on the influence of sewage irrigation on the soil heavy metal elements, but also with the soil of various mineral compositions in soil materials in the inheritance. Only in the research of soil mineral composition and source and analyzing the change of the soil heavy metal element content, we can correctly evaluated on the soil heavy metal.

\subsubsection{Soil Heavy Metal Primary Release Source}

1. Comes from the Pedogenic parent material- - heavy metal in ore body of surrounding rock

The average content of heavy metal elements which is in the mining area and the periphery of various kinds of rock of $\mathrm{Pb}, \mathrm{Cu}$ and zinc, $\mathrm{Mn}$ and $\mathrm{Ni}$ etc. were determined and analyzed by predecessors. the analysis results show that the content of heavy metal elements, such as $\mathrm{Cu}, \mathrm{Pb}$, zinc in different surrounding rock of the Dabaoshan mining area are number times to hundreds times higher than the average content in the earth's crust (Clarke value) (Tab. 1). It shows the area of surrounding rock is the sources of the original of $\mathrm{Cu}, \mathrm{Pb}$ and zinc. So the $\mathrm{Pb}, \mathrm{Cu}$ and zinc content in the soil which these rocks as pedogenic parent material is higher.

Table 1. Geometric average content and the concentration Clarke value of heavy metal element from surrounding rock of Dabaoshan mining area [1].

\begin{tabular}{|c|c|c|c|c|c|c|}
\hline Rock Name & $\mathbf{C u}$ & & $\mathbf{P b}$ & & Zn & \\
\hline & $\bar{x}$ & $\Delta c$ & $\bar{x}$ & $\Delta c$ & $\bar{x}$ & $\Delta c$ \\
\hline arenaceous shale & 253 & 4.4 & 2416 & 120 & 2366 & 29.6 \\
\hline manganic rook & 5760 & 101 & 4260 & 213 & 4363 & 54.5 \\
\hline siltstone & 657 & 11.5 & 728 & 104 & 542 & 36 \\
\hline clay rock & 5750 & 23 & 4500 & 56 & 966 & 5.8 \\
\hline tuff & 342 & - & 1157 & - & 1835 & - \\
\hline manganese sand shale & 1675 & 37 & 4930 & 246 & 1510 & 15.8 \\
\hline Peaty limestone & 27.5 & 6.8 & 109 & 12 & 124.4 & 6.2 \\
\hline quartz sandstone & 45.6 & 1 & 20.6 & 2.9 & 58.1 & 3.8 \\
\hline secondary dacite-porphyry & 24.1 & 1.2 & 25.3 & 1.3 & 23.1 & -2.5 \\
\hline Granodiorite porphyry & 10 & -2 & 20 & 1 & 8 & -7.5 \\
\hline
\end{tabular}

Remarks: 1. $\bar{x}$ is the geometric average content of heavy metal elements (unit: $\mathrm{mg} / \mathrm{kg}$ );

2. $\Delta c$ is concentration Clarke, that is greater than Clarke value multiples, Greater than the multiples for the plus sign" +", Less than a multiple for the minus sign "-";

3. Clarke number: according to Vinogradov (1962), TuLiqian and FeiDeBo (1961);

2. Comes from the Pedogenic Parent Material--Heavy Metal in Ore

Material composition effects on soil chemical composition of ore are very obvious. Dabaoshan ore type is more, both from magmatic rocks and from sedimentary rocks. The heavy metal element combinations of difference ore type is very big different (Table 2). Mining area of $\mathrm{Cu}, \mathrm{Pb}$ and zinc had formed separate deposits, $\mathrm{Cu}, \mathrm{Pb}$ and zinc content in the ore deposit is higher than the non-mine soil, the average abundance value is much higher than the earth's crust. As a result, the mineral weathering and its exploitation will lead to the release of heavy metals, leaching, denudation, erosion and carry, gradually deposited along the mountain slope, Hengshi river on both sides of the terraces and flood land, caused enrichment of heavy metals by the mineralized bodies into the surrounding soil environment migration and diffusion, become an important source of soil heavy metal elements at Dabaoshan mine

\subsubsection{Soil Heavy Metal Secondary Source Release}

Table 2. Geometric average of heavy metal element of Dabaoshan ore.

\begin{tabular}{|c|c|c|c|c|}
\hline Ore Name & Wallrocks Ore & $\mathbf{C u}$ & $\mathbf{P b}$ & $\mathbf{Z n}$ \\
\hline \multirow[t]{3}{*}{ Molybdenum ores } & secondary dacite-porphyry & 25.8 & 25.2 & 16.2 \\
\hline & granodiorite porphyry & 21 & 10.0 & 18.9 \\
\hline & Limestone of Qiziqiao Formation & 17.9 & 20.3 & 12.3 \\
\hline \multirow[t]{2}{*}{ Brass ore } & secondary dacite-porphyry & 1847 & 243 & 58.4 \\
\hline & Limestone of Qiziqiao Formation & 4591 & 414 & 38.5 \\
\hline Brass Lead-Zinc Ore & Limestone of Qiziqiao Formation & 9815 & 6857 & 1090 \\
\hline
\end{tabular}

1. From beneficiation activities - the heavy metals of mine tailing

The particle size of mine tailings from beneficiation activities as much as fine sand and silt contains a lot of pyrite, pyrrhotite, sphalerite, chalcopyrite, galena, a set of metal sulfides. Along with wastewater migrated to the downstream rivers and soil environment, become a direct source of pollution. Sample analysis shows that the heavy metal content of $\mathrm{Pb}, \mathrm{Cd}$ and $\mathrm{Cu}$ in two tailings is difference very much. They are mainly caused by difference tailing ore source (Table 3 ). 
Table 3. The average content of heavy metal at Dabaoshan tailings (Unit: $m g / k g)$.

\begin{tabular}{lllll}
\hline Sampling point & Pb & Cd & Cu & Zn \\
\hline Fandong tailing & 368.6 & 4.02 & 1058.74 & 1273.94 \\
Tie long tailing & 995.4 & 17.30 & 398.78 & 1318.3 \\
Sampling point & $\mathrm{Cr}$ & $\mathrm{Mn}$ & $\mathrm{Ni}$ & \\
Fandong tailing & 15.07 & 297.38 & 9.00 & \\
Tie long tailing & 41.07 & 362.21 & 14.20 & \\
\hline
\end{tabular}

2. From the Wastewater of Tailings
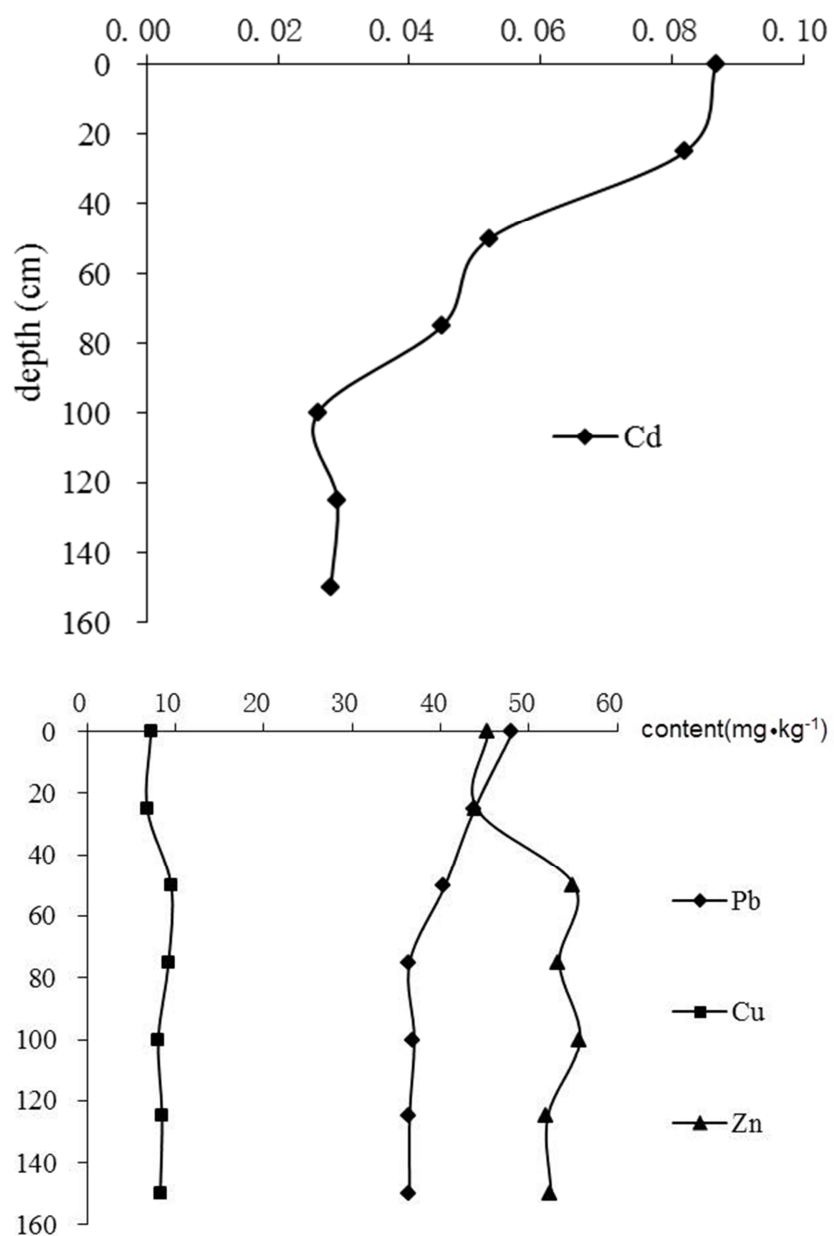

Figure 3. The soil heavy metal content distribution on the vertical profile of Chen Gong River.

A large number of acid mine water which rich heavy metals element such as $\mathrm{Pb}, \mathrm{Cd}, \mathrm{Cu}$, zinc, $\mathrm{Cr}$ and $\mathrm{Mn}$ is released in the process of mining. The waste water overflow dam, import Hengshi River, and become an important source of pollution of the downstream water and the soil. Because FanDong tailing mainly pile up copper mine backfilling, while Tie Long tailing mainly pile up iron mine backfilling materials, thus cause the two heavy metal content in tailings of mine wastewater showed different distribution characteristics (Table 4).
Table 4. The geometric average of heavy metal content of wastewater at Dabaoshan tailings (unit: $\mathrm{mg} / \mathrm{L}$ ).

\begin{tabular}{lllll}
\hline Sampling point & $\mathbf{p H}$ & $\mathbf{P b}$ & $\mathbf{C d}$ & $\mathbf{C u}$ \\
\hline Fandong tailing & 2.93 & 0.45 & 0.14 & 6.60 \\
Tielong tailing & 3.14 & 0.43 & 0.48 & 3.53 \\
Sampling point & $\mathrm{Zn}$ & $\mathrm{Cr}$ & $\mathrm{Mn}$ & \\
Fandong tailing & 9.83 & 0.05 & 38.66 & \\
Tielong tailing & 28.4 & 0.04 & 31.37 & \\
\hline
\end{tabular}

\subsection{The Migration and Distribution Characteristic of the Soil Heavy Metal on Both Sides of Hengshi River}

\subsubsection{The Background Value, as the Background Value and Contrast Value}

Because the environment pollution was caused by human activities, it is difficult to find the background value which can reflect the original material composition, properties and structure characteristics of the soil environment, and to determine the extent of the pollution caused by human activities. So although main soil types of Dabaoshan area is red soil, the background values of heavy metals at Shao guan area of Guangdong province can be used for reference, but in order to further research the distribution and migration characteristics of heavy metals in soil environment of Dabaoshan mine area. This paper, the Chen Gong river village as a contrast area which is not affected by mining activities but its pedogenic environment, atmospheric environment, farming method, pesticide and chemical fertilizer are same or similar to the study area. To choose the heavy metal element content average value of contrast area that the content at this the vertical section depth tend to stable invariant as the resembling background value, to choose the average content of soil heavy metal within the scope of the depth of plough layer of contrast area as contrast value to judge the degree of heavy metal pollution (Figure 3).

The Figure 3 shows that on the vertical section, the content of $\mathrm{Pb}$ and $\mathrm{Cd}$ in soil plough layer $(0-30 \mathrm{~cm})$ is highest, with the increase of depth, heavy metal content showed a trend of fluctuation is reduced; And the content of $\mathrm{Cu}$ and zinc in the soil plough layer $(0-30 \mathrm{~cm})$ is lower, with the increase of depth, the trend of the heavy metal content was increased fluctuate, the content reach the highest at $50 \mathrm{~cm}$ depth, below $60 \mathrm{~cm}$ depth, the content tend to stable invariant be stable gradually. Under section $100 \mathrm{~cm}$ depth, $\mathrm{Pb}, \mathrm{Cd}, \mathrm{Cu}$ and zinc element content changes almost stable invariant, it shows that the soil heavy metal content is influenced by the outside is not obvious below the depth, it reflects the nature of soil heavy metal content. this phenomenon shows the condition of the soil by ChenGong river basin, the vertical migration ability of $\mathrm{Pb}$ and $\mathrm{Cd}$ element are relatively strong, the depth reach to $100 \mathrm{~cm}$; And the vertical migration ability of $\mathrm{Cu}$ and zinc element are relatively weak, only reach to $60 \mathrm{~cm}$. the soil heavy metal content of $\mathrm{Pb}, \mathrm{Cd}, \mathrm{Cu}$ and zinc elements is no 
longer clear change below $100 \mathrm{~cm}$. therefore, the heavy metal content within the scope of this depth is no longer affected by human activities. This reflects the natural state of soil content, so the heavy metal content in this depth would be a judge value to Hengshi river basin as the resembling background value of soil is affected by human activities (Table 5).

Table 5. The evaluating value of soil heavy metals in the study area (unit: $m g / k g)$.

\begin{tabular}{lllll}
\hline Evaluation Index & $\mathbf{P b}$ & $\mathbf{C d}$ & $\mathbf{C u}$ & $\mathbf{Z n}$ \\
\hline $\begin{array}{l}\text { red soil background values of Shao } \\
\text { guan of Guangdong [1] }\end{array}$ & 34.38 & 0.03 & 14.38 & 48.75 \\
$\begin{array}{l}\text { As background values (100cm depth } \\
\text { of soil by Chengong river) }\end{array}$ & 37.03 & 0.03 & 8.50 & 63.8 \\
$\begin{array}{l}\text { plough layer contrast value (0-30cm } \\
\text { depth of soil by Chengong river) }\end{array}$ & 48.2 & 0.09 & 11.25 & 45.4 \\
$\begin{array}{l}\text { the state soil environment quality } \\
\text { secondary standard (pH }<6.5)\end{array}$ & 250 & 0.3 & 50 & 200 \\
\hline
\end{tabular}

Table 5 shows: the average content of $\mathrm{Cd}$ and $\mathrm{Pb}$ element of plough layer in the study area were higher than red soil background values of Shao guan of Guangdong, and as the resembling background value close to the red soil background values of Shao guan of Guangdong. So the contrast area plough layer affected by human activities.
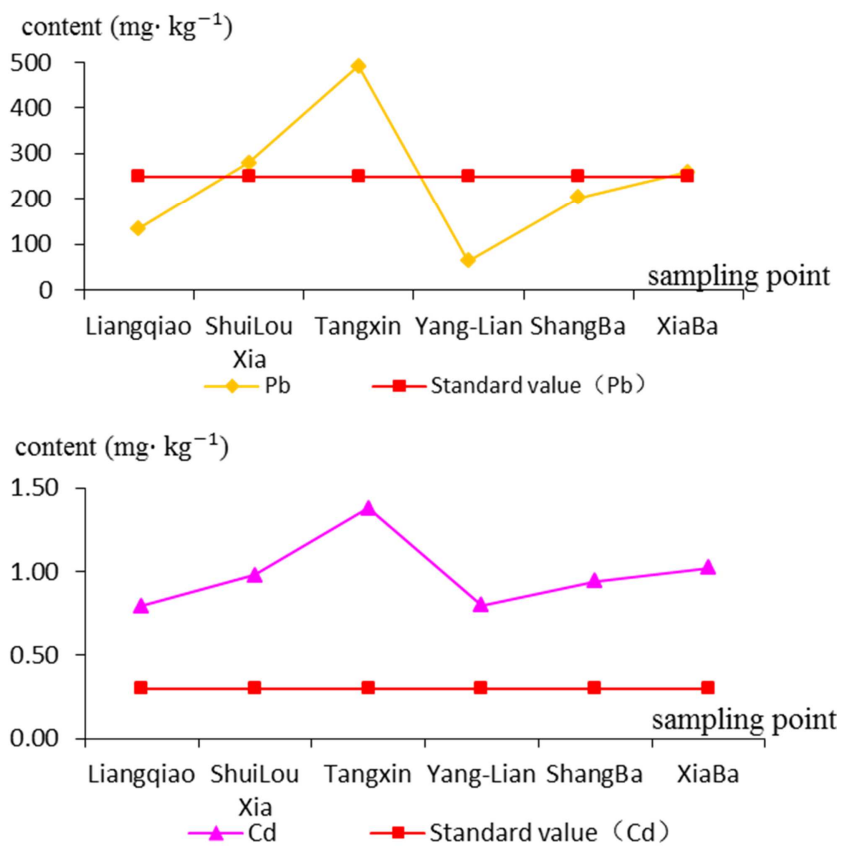

content $\left(\mathrm{mg} \cdot \mathrm{kg}^{-1}\right)$

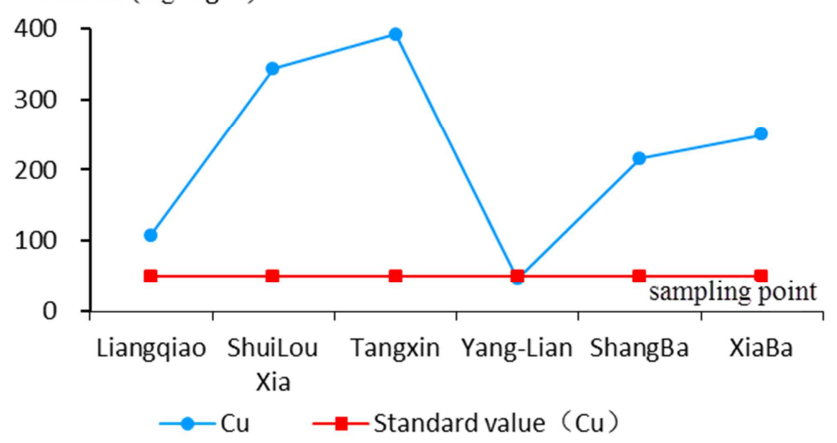

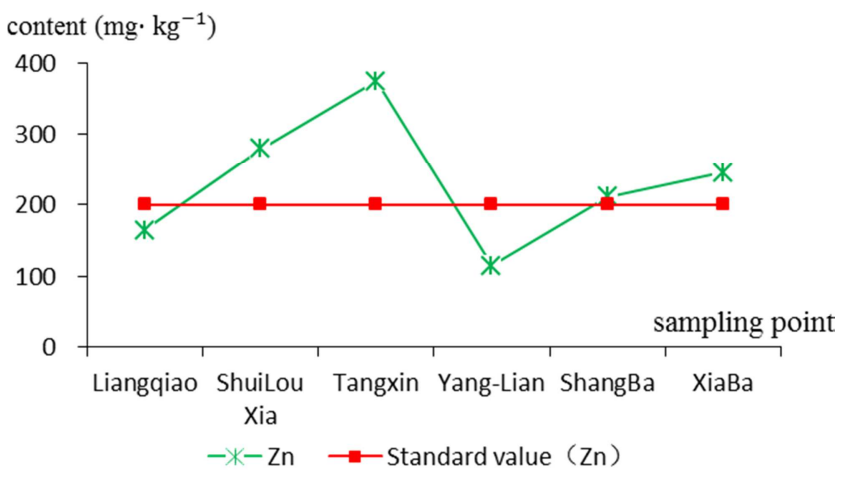

Figure 4. The migration and distribution characteristics of the surface soil heavy metal element along the rivers.

The average content of $\mathrm{Pb}, \mathrm{Cd}, \mathrm{Cu}$ and zinc element in the plough layer of the study area were significantly higher than the contrast value of Chen Gong River's village which is not affected by mining activities. This description that there are many higher content heavy metal from waste residue, acidic waste water discharge of Dabaoshan mining activities, along the Hengshi river irrigation farmland caused by pollution of heavy metal content.

\subsubsection{The Migration and Distribution Characteristics of Soil Heavy Metal}

Heavy metal element migration and distribution is influenced by many factors, such as $\mathrm{PH}$, clay content, organic matter content and soil coexist elements, etc. there are 3 space patterns of migration for horizontal, vertical migration of rivers and vertical ground migration. From the theory analysis, with the horizontal longitudinal flow along the river, the characteristics of migration and distribution of soil heavy metal content is reduced gradually from the river upstream to the downstream areas; In vertical on the level of the river section, the more far away from the river on both sides of the soil, the content of heavy metal migration and distribution is characterized by reduced gradually. Content in the migration and distribution of the vertical section should be characterized by: heavy metal content is the highest soil, with the increase of the depth of the heavy metal content is a trend of decrease, gradually close to the background value or the resembling background value. But the soil of the Dabaoshan mining are affected by sewage irrigation, topography and soil heavy metal activity, it shows different characteristics of migration and distribution.

1. The surface migration and distribution characteristics of soil heavy metals

(1) Along the river migration: Tab. 6 and Fig. 4 can be seen $\mathrm{Pb}, \mathrm{Cd}, \mathrm{Cu}$ and zinc element average excess standard multiples are: 1.2 times, 2.8 times, 4.2 times and 1.2 times in the Hengshi River sewage influence area, surface soil in the study area have been the effects of $\mathrm{Pb}, \mathrm{Cd}, \mathrm{Cu}$ and zinc element, give priority to with $\mathrm{Cd}$ and $\mathrm{Cu}$ pollution, secondary is $\mathrm{Pb}$ and zinc pollution. The most polluted is TangXin village. 
Table 6. The contrastive analysis to the surface soil heavy metal content along the Hengshi River.

\begin{tabular}{lllll}
\hline \multirow{2}{*}{ element } & \multicolumn{2}{l}{ index } & & \\
\cline { 2 - 5 } & Pb & Cd & Cu & Zinc \\
\hline maximum & 900.06 & 3.88 & 616.44 & 588.56 \\
minimum & 18.61 & 0.24 & 14.66 & 69.85 \\
average & 288.05 & 0.84 & 210.38 & 241.22 \\
average excess multiples & 1.2 & 2.8 & 4.2 & 1.2 \\
\hline
\end{tabular}

(2) Vertical longitudinal flow cross the river migration: at Shangba village of about $14.9 \mathrm{~km}$ away from the Tie Long tailings, the samples from vertical longitudinal flow cross the river were analyzed. The section line of Fig. 5 of about $14.9 \mathrm{~km}$ away from Tie Long tailing, the left bank is mainly affected by Chen Gong river, the right bank is mainly
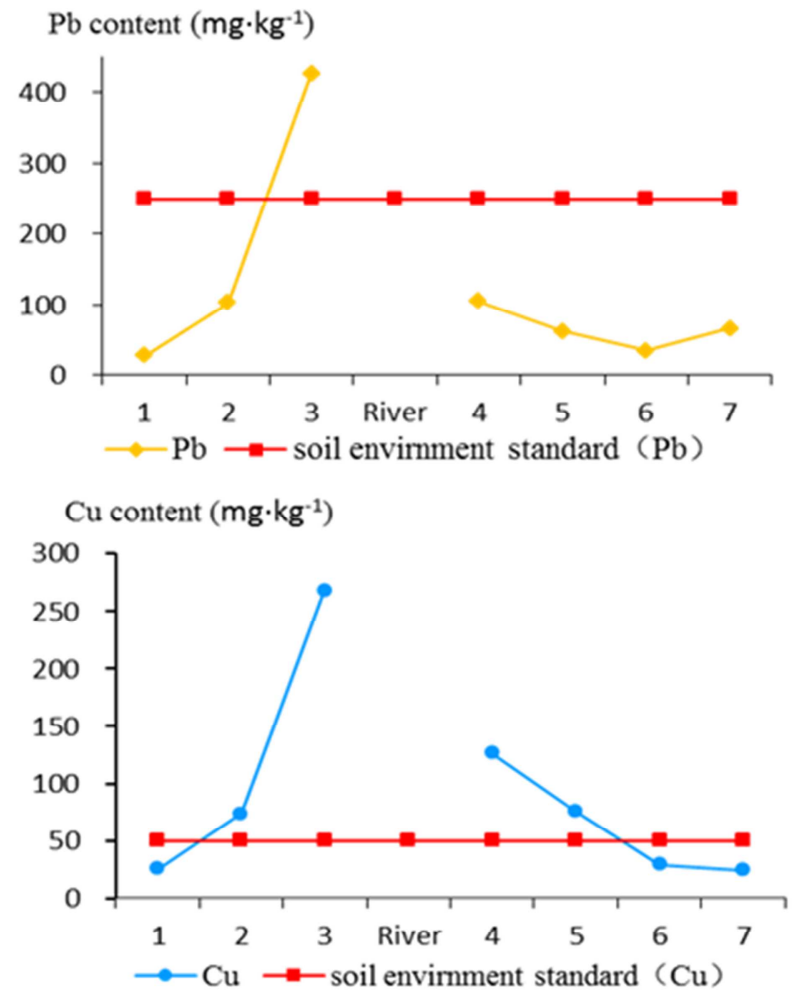

affected by Hengshi river. Therefore, the left bank of the heavy metal elements $\mathrm{Pb}, \mathrm{Cu}$ and zinc do not exceed the standard, the content of $\mathrm{Cd}$ also show only slightly overweight 1.4 times; the right bank section show that the heavy metal element content close to Hengshi river banks, the heavy metal content is higher. The right bank of the surface soil heavy metals content $\mathrm{Pb}$ does not exceed the standard, and near the banks of the river in the surface soil $\mathrm{Cu}$ and zinc content is more than standard values, a multiple of 3.1 times and 1.1 times respectively, the right bank of surface soil heavy metals $\mathrm{Cd}$ content than standard value, maximum is a multiple of 1.8 times standard valued. Thus, the surface soil heavy metal pollution status of this section line is given priority to with $\mathrm{Cd}$ pollution, $\mathrm{Cu}$ pollution is secondary.

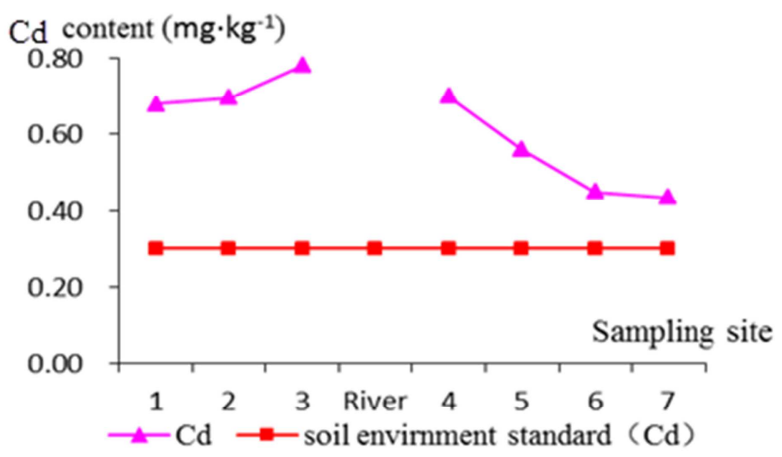

Zinc conteng $\left(\mathrm{mg} \cdot \mathrm{kg}^{-1}\right)$

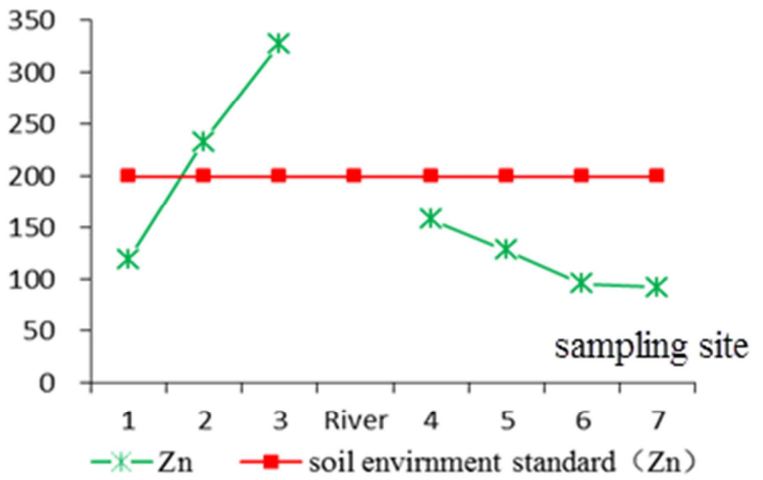

\section{$1 \leftarrow 420 \mathrm{~m} \rightarrow 2 \leftarrow 390 \mathrm{~m} \rightarrow 3 \leftarrow 20 \mathrm{~m} \rightarrow$ River $\leftarrow 200 \mathrm{~m} \rightarrow 4 \leftarrow 350 \mathrm{~m} \rightarrow 5 \leftarrow 230 \mathrm{~m} \longrightarrow 6 \leftarrow 410 \mathrm{~m} \longrightarrow 7$}

Vertical river flow, the space of sampling site (left bank $\rightarrow$ right bank), about $14.9 \mathrm{~km}$ away from the Tie Long tailings

Figure 5. The migration and distribution characteristics of the surface soil heavy metal element for vertical rivers.

2. The migration and distribution characteristics for profile of soil heavy metal

Figure 6 is different distribution characteristics of heavy metal element for vertical profile at Shangba village of 7 sampling point. Because the study area is located in the alluvial plain, most of the sampling points are preferable to deep vertical soil samples of $150 \mathrm{~cm}$.

As can be seen from the Figure 6:

(1) The $\mathrm{Pb}$ content of surface soil isn't larger than standard value, with the increase of depth; the content of $\mathrm{Pb}$ basic stable, its content is lower than the standard values. Illustrate the $\mathrm{Pb}$ element partition in the research the basic characteristics of no pollution;

(2) the Cd content of surface soil is larger than standard value, with the increase of depth, the content of $\mathrm{Cd}$ element reduce gradually, till $125 \mathrm{~cm}$, its content tend to be standard value, but $150 \mathrm{~cm}$ depth, there are still a part of the $\mathrm{Cd}$ content of soil is not stable, this explain $\mathrm{Cd}$ element of 
vertical migration distance is far, move faster, easier migration characteristics;

(3) the $\mathrm{Cu}$ content of most of the surface soil is larger than standard value, with the increase of depth, the content of $\mathrm{Cu}$ element gradually reduce, but till $150 \mathrm{~cm}$ depth, there are still a part of soil $\mathrm{Cu}$ content is not stable, this explain $\mathrm{Cu}$ element of vertical migration distance is far, move quickly, easy to the characteristics of the migration;

(4) the zinc content of most of the surface soil is larger than standard value, with the increase of depth, the content of zinc element gradually reduce, till $125 \mathrm{~cm}$, its content tend to be standard value; till $150 \mathrm{~cm}$ depth, there are still a part of soil Zinc content is not stable, this explain $\mathrm{Cu}$ element of vertical migration distance is far, the features of moving faster.

From the above analysis: in soil vertical section, the release of the heavy metal content and spatial distribution characteristics follow the above theory, but in longitudinal and transverse section along the river flow, is not follow the rules of the spatial distribution, long-term wastewater irrigation to carry a large amount of slime and suspended material into the soil, physical accumulation process of heavy metals are not single, but by dissolution, precipitation, coagulation, complexation, and adsorption all sorts of chemical reaction, such as formation of different chemical forms, thus the pollution caused by excessive. The degree of pollution is affected and controlled by many factors.

Mobility analysis: the heavy metals element of Dabaoshan sewage irrigation area, from upstream to downstream show different potential soil heavy metal migration sequence, especially in Shangba village sewage irrigation area, the migration ability of heavy metals are present a $\mathrm{Cd}>\mathrm{Cu}>\mathrm{Pb}>$ zinc. Although reveals that the total amount in Shangba $\mathrm{Cd}$ is not large, but its potential ability to migrate, the strongest polluting is the highest; $\mathrm{Cu}$ and $\mathrm{Pb}$ also has strong potential ability to migrate, zinc potential migration ability are relatively weak. Thus further illustrate in Shangba village of Dabaoshan, Cd element need to priority control of heavy metal elements at Dabaoshan sewage irrigation area.

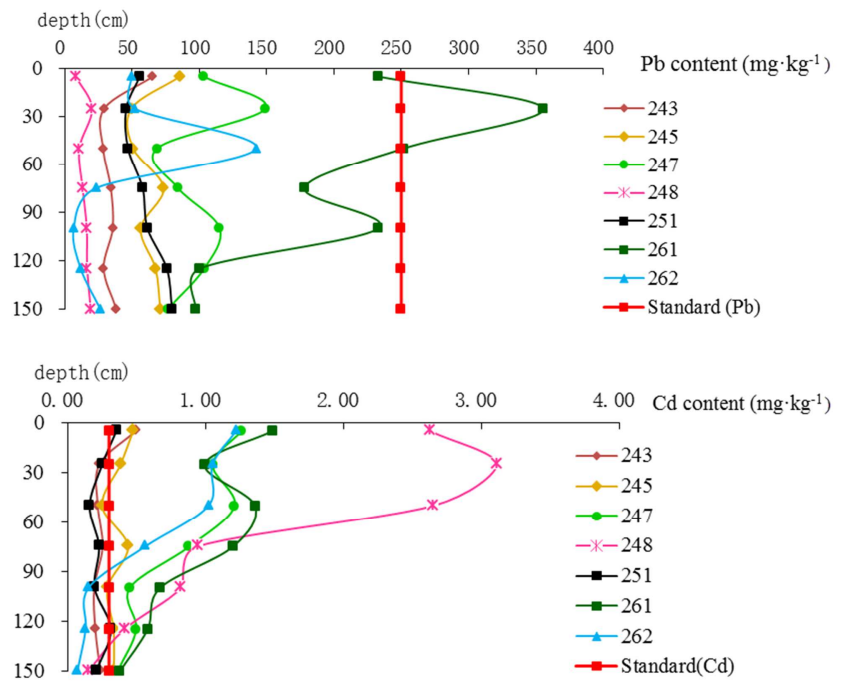

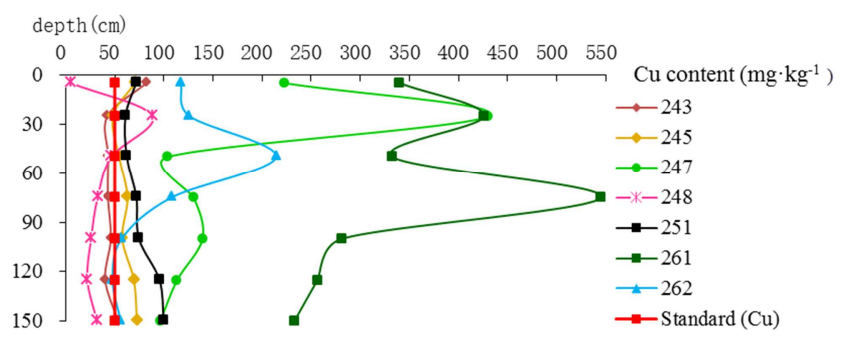

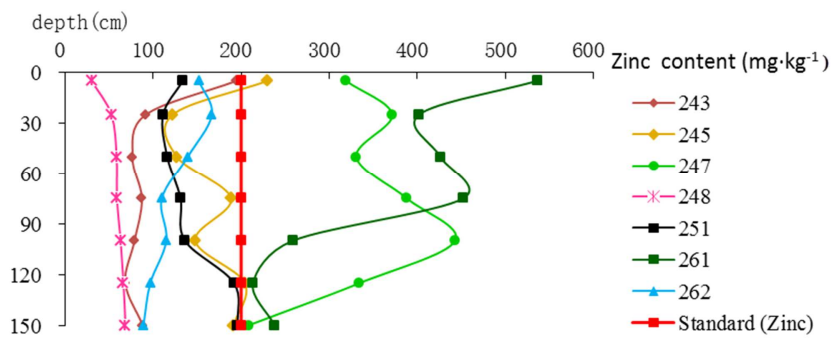

Figure 6. Migration and distribution characteristics of soil heavy metal element for vertical section.

\section{Conclusion}

1. The heavy metals pollution source of Dabaoshan mine is high background values and the superimposition and accumulation of pollution caused by mining activities.

2. The migration ability of heavy metals in Dabaoshan soil is $\mathrm{Cd}>\mathrm{Cu}>\mathrm{Pb}>$ zinc.

3. The $\mathrm{Cd}$ element has to be considered as an optimization control of soil restoration governance elements for Dabaoshan area.

\section{Acknowledgements}

Aid financially project: public welfare project of Ministry of Land and Resources (No: 201111020-7).

\section{References}

[1] Qiu Shiqiang. A preliminary study on the genesis of the Dabaoshan strati form polymetallic deposit [J]. Geological Review, 1981, 27 (4): pp. 333 340.

[2] Luo Nianhua. The Geological and Geochemical Features and the Origin of Dabaoshan Polymetallic Deposit in Guangdong Province. [J]. Journal of Guilin college of geology, 1985, 5 (2): pp 184 195.

[3] Liu Xiaoshan, Zhou Shunzhi. On the occurrence of middle Ordovician volcanic and analysis of ore-forming mechanism of siderite poly-metallic of deposit from Dabaoshan, qujiang county Guangdong province [J]. Journal of Nanjing University (Natural Sciences Edition), 1985, 21 (2): pp 349 362.

[4] Liu Houqun, Yang Shiyi, Zhang Xiulan. A Preliminary Study on the Genesis of the Dabaoshan Polymetallic Deposit in Northern Guangdong [J]. Journal of Geology, 1985, (1): 47 61. R. Nicole, "Title of paper with only first word capitalized," J. Name Stand. Abbrev.

[5] Zhuang Ming Zhen. Discussion on Metallogenic Condition and Ore Genesis of Polymetallic Deposit of Dabaoshan [J]. Geology and Prospecting, 1986, (5): pp 27 31. 
[6] Huang Shujun, Zeng Yongchao, Jia Guoxiang. On the Genesis of Dabaoshan Polymetallic Deposit in Guangdong Province [J]. Geochemical, 1987, (1): pp 27 35

[7] Yao Dexian, Zen Lingchu. On Genesis of Dabaoshan Mineral Deposits [J]. Act Scientia rum Naturalium Universitatis Sunyatseni, 1994, 33 (3): pp 91 100.

[8] Wu Yonggui, LIN Chu-xia, TONG Xiao-li. Environmental impacts of acid mine drainage from the Dabaoshan Mine: I. Downstream aquatic ecosystem [J]. Ecology and Environment 2005, 14 (2): pp 165 168.

[9] LIN Chu-xia, LU Wen-zhou, WU Yong-gui. Environmental impacts of acid mine drainage from the Dabaoshan Mine: II. Agricultural ecosystem [J]. Ecology and Environment, 2005, 14 (2): pp 169 172

[10] CAI Mei-fang, DANG Zhi, WEN Zhen. Risk assessment of heavy metals contamination of soils around mining area $[\mathrm{J}]$. Ecology and Environment 2004, 13 (1): pp 6 8.

[11] Zhou Jianming, Danzhi, Si Tuyue. Distribution and Characteristics of Heavy Metals Contaminations in Soils from Dabaoshan Mine Area [J]. Journal of Agro-Environment Science, 2004, 23 (6): 1172 1176.

[12] Yang Zhen, Hu Mingan. Environment Investigation of Heavy Metal Pollution from $M$ inning in Dabaoshan [J]. Environmental monitoring and manage technology, 2006, 18 (6): 21 24.

[13] CHEN Qing-min, ZHANG Xiao-jun, HU Ming'an. Assessment of Aquatic Pollution of Heavy Metals in a Copper- iron Area [J] Environmental Science and Technology, 2006, 29 (6): 64 67.

[14] Xu Chao, Xia Beicheng, Qing Jianqiao. Analysis and Evaluation on Heavy Metal Contamination in Paddy Soils in the Lower Stream of Dabaoshan Area, Guangdong Province [J] Journal of Agro-Environment Science, 2007, 26 (Supplement): 549 553.

[15] Xu Chao, Xia Beicheng. Ecological risk assessment of heavy metals in paddy soils contaminated by acid mine drainage with toxicity characteristic leaching procedure [J]. Ecology and Environment 2008, 17 (6): 2264 2266.

[16] Xu Chao, Xia Beicheng, He Shimei. Characteristics of Cd, Zn, $\mathrm{Pb}, \mathrm{Cu}$ Content of Paddy Soils in the $\mathrm{L}$ owerStream of Dabaoshan Area, Guangdong [J]. Act Scientia rum Naturalium Universitatis Sunyatseni, 2008, 47 (3): 122 127.

[17] Xu Chao, Xia Beicheng, Wu Haining. Speciation and Bioavailability of Heavy Metals in Paddy Soil Irrigated by Acid Mine Drainage [J]. Environmental Science, 2009, 28 (11): 2293 2296.

[18] ZOU Xiao-jin, QIU Rong-liang, HUANG Sui-hong. Immobilization and re-vegetation of heavy metal polluted soils in Dabaoshan, Guangdong Province by amendments [J]. China Environmental Science, 2008, 28 (9): 775 780.

[19] Qiu Yinghua, Wu LingFang, Liao Linjuan. Analysis of Vegetation Actuality and Restoration in Dabaoshan Mining Field, Guangdong Province. [J]. Forestry Science and Technology of Guangdong Province, 2010, 26 (5): 22 27.
[20] Rudnick and Gao. Composition of the Continental Crust [C]. Elsevier Pergamon, Holland and Turekian. 2004, (3), 1-64.

[21] Zhen Jiajia, Jiang Xiao, Zhang Xiaojun. Pollution Assessment of Heavy Metals in Soil around Dabaoshan Polymetallic Ore Deposit [J]. Environmental Science \& Technology, 2008, 31 (11): 137-145.

[22] Zhou Jianming, Dang Zhi, Cai MeiFang. Speciation Distribution and Transfer of Heavy Metals in Contaminated Stream Waters around Dabaoshan Mine [J]. Research of Environmental Sciences, 2005, 18 (3): 5-10.

[23] Xu Lianfeng, Liu Tenghui. The Zonal Differentiation of Soil environmental Background Values and Critical contents in Guangdong [J]. J. South China g r. Univ., 1996, 17 (4): 58 62.

[24] Duan Xinchun, Wang Wenjin, Dang Zhi. Distribution of Heavy metals in water around the Daobaoshan mine [J]. Earth and Environment, 2007, 35 (3): 255 260.

[25] Zhou Xiaojin, Qiu Rongliang, Zhou Xiaoyong. Heavy metal contamination and health risk assessment in Dabaoshan, China [J]. Acta Scientiae Circumstantiae, 2008, 27 (4): 855 862.

[26] Li Yongtao, Thierry Becquer, C•cile Quantin. Effects of heavy metals on microbial biomass and activity in subtropical paddy soil contaminated by acid mine drainage [J]. Acta Ecologica sinica, 2004, 24 (11): 2430 2436.

[27] Abundance in Earth's Crust. WebElements.com. 2007-04-14.

[28] CHEN Sanxiong, XIE Li, CHEN Jiadong. Evaluation on soil heavy metal pollution at Dabaoshan mine in Guangdong province [J]. Journal of Nanjing Forestry University (Natural Science Edition), 2012, 36 (3): 59 63.

[29] Xu Youning, Zhang Jianghua, Ke Hailing. Cd contamination of farmland soil in a gold mining area and its environmental effects [J]. Geology in China, 2013, 40 (2) 636 643.

[30] Su Wenji, Xu Youning, Fu Shanming. The distribution regularity and accumulation risk of heavy metals in water and soil along the Hengshi River in the Dabaoshan mining area, Guangdong Province. Geological Bulletin of China, 2014, 33 (8): 1231-1238.

[31] SU Wenji, FAN Sheng. Analysis and evaluation of heavy metal pollution along the river of Dabaoshan mine area $[\mathrm{J}]$. Hebei Journal of Industrial Science and Technology, 2014, Vol. 31 (3): 199-203.

[32] QIU Jinquan, FU Shanming, SU Wenji. Characteristics and Significance of Copper Eco-geochemistry in Soil of Hengshi River Basin in the Dabaoshan Mine, Guangdong Province [J]. Ecology and Environmental Sciences, 2015, 24 (10): 1695-1704.

[33] QIU Jinquan, FU Shanming, Xiao Fang, SU Wenji. Prediction and Ecological Risk Warning Assessment of Heavy Metals in Soil of Hengshi River Basin in the Sulfide Mine, Northern Guangdong Province, China [J]. Earth and Environment. 2015, Vol. 43 (3): 338-344. 